\title{
The Relationship between Family's Social Economic Status and Psychological Suzhi of Middle School Students: The Intermediary Effect of Parenting Style
}

\author{
Zesong Dong, Dajun Zhang \\ Mental Health Education Research Center, Southwest University, Chongqing, China \\ Email:dzs9904@126.com
}

Received 17 November 2015; accepted 13 December 2015; published 16 December 2015

Copyright ( 2015 by authors and Scientific Research Publishing Inc.

This work is licensed under the Creative Commons Attribution International License (CC BY). http://creativecommons.org/licenses/by/4.0/

(c) (i) Open Access

\begin{abstract}
This research focused on the relationship among family's social economic status (SES), parenting style and psychological suzhi of middle school students. The results indicated that SES has significant positive correlation with middle school students' psychological suzhi; parenting style significantly predicts psychological suzhi of middle school students; among them, mother's emotional warmth and father's emotional warmth significantly positively predict psychological suzhi; mother's rejection and father's over protection significantly negatively predict psychological suzhi. SES not only has independent prediction effect on middle school students' psychological suzhi, but also positively predicts psychological suzhi through father's emotional warmth and mother's emotional warmth by intermediary role.
\end{abstract}

Keywords

Family's Social Economic Status, Parenting Style, Psychological Suzhi, Middle School Students

\section{Introduction}

Psychological suzhi is the localized concept put forward under the background of quality education in China. It means on the basis of the physiological condition, the externally obtained stimulus is internalized into the stable, basic and implicit psychological quality, including cognitive quality, personality quality and adaptability quality [1]. The current related research of psychological suzhi is mainly the analysis on and discussion about the function value and mechanism of action of psychological suzhi [2], and the investigation on the formation and de- 
velopment of affecting factors of psychological suzhi is relatively rare. In recent years, the differentiation of family's social economic status can have an important impact on the development of youngsters. This phenomenon has drawn the high attention of academic circle [3]. The family's social economic status (SES) refers to the hierarchical ranking of according to the valuable resources obtained or controlled by family (such as education, occupation, family income, etc.). It reflects the individual's difference in obtaining real or potential resources [4]. As a comprehensive index, SES is an effective and stable variable that can represent the family environment [5]. Therefore, exploring the relationship between SES and middle school students' psychological suzhi is the internal requirement of revealing the relationship between family microsystem and psychological suzhi. In addition, some researchers have pointed out that SES and parenting style are two important variables in the family system, and their relationship should not be treated separately [6], because lower SES will not necessarily lead to the development risk of children, and its mechanism of action tends to be affected by factors such as parenting style [7]. It also suggests that SES and parenting style should be incorporated into the discussion about the relationship between family environment and psychological suzhi. Based on the above analysis, this study attempts to examine the internal mechanism of the relationship between SES and middle school students' psychological suzhi, namely the intermediary effect of parenting style on SES and middle school students’ psychological suzhi.

\section{Methodology}

\subsection{Instrument}

SES questionnaire [7]. The participants reported their parents' occupations and education level. In accordance with the relevant criteria for the occupational classification, father's occupation and mother's occupation were encoded and translated into the corresponding grades respectively. And finally the values of occupation level and education level were added. The total score was the index of family's social economic status. Its distribution range was 4 - 22. This study referred to Gong's study and SES was divided into high, middle and low grade [5]. Those with 18 points and above were high SES families, those with 12 (including 12 points) - 17 points (including 17 points) were the middle SES families, and those with 11 points and below were low SES families. Chinese Version of Simplified Parents Parenting Questionnaire (S-EMBU-C) [8]. For the questionnaire, children evaluated their parenting style. The questionnaire is divided into father version and mother version, including 21 items with the same content. There are three dimensions, which are Emotional Warmth, Rejection and Over Protection. The questionnaire uses four-point score from "never" to "always”. The higher the score is, the more parents' emotional warmth is felt, and the more parents' rejection and over protection degree is felt. This study showed that the internal consistency coefficient of father's emotional warmth, mother's emotional warmth, father's rejection, mother's rejection, father's over protection, mother's over protection was 0.81, 0.72, 0.75, 0.74, 0.80 and 0.73 respectively. Middle School Students’ Psychological Suzhi Questionnaire [9]. The questionnaire includes cognition, personality and adaptability. There are 34 questions, and 5-point scale is used from "strongly disagree” to "totally agree”. Among them, Question 5, 8, 11, 14, 17, 23 and 29 have reverse score. The higher the score is, the better psychological suzhi is. In this study, the total points and internal consistency coefficient of cognition, personality and adaptability of middle school students' psychological suzhi questionnaire was 0.88 , $0.86,0.84$ and 0.80 , respectively.

\subsection{Participants}

1995 questionnaires were issued in this survey. 1907 effective questionnaires were collected. The effective collection rate was 95.61\%. The age range was 10 - 19 (15.18 \pm 1.83$)$ years old. There were 890 boys and 1017 girls.

\subsection{Survey Procedures}

Based on the principle of stratified random sampling, sampling and survey was conducted in the urban and rural middle schools in Dali Bai Nationality Borough in Yunnan respectively. The survey method was group survey. The experimenters were psychology graduate students who have received the strict training. In the survey, the participants were required to read the instructions carefully, and then fill in the questionnaire according to the requirements. The survey time was about 35 minutes. All the questionnaires were collected on the spot. 


\subsection{Data Analysis}

SPSS16.0 was used for statistical processing and analysis of data, mainly including descriptive statistics, correlation analysis and multiple linear regression analysis.

\section{Results}

\subsection{Analysis on Correlation of SES and Middle School Students' Psychological Suzhi}

The correlation of SES and middle school students' psychological suzhi was calculated. It was found that the two had significant positive correlation $(r=0.33, p<0.001)$. To verify the relationship more visually, SES classification (including high, middle and low level) was considered as the independent variable, and total score of middle school students' psychological suzhi was considered as the dependent variable for the one-way analysis of variance. The results showed that the classification effect of SES was significant $(F=68.15, p<0.001)$; subsequent multiple comparisons also showed that psychological suzhi of low SES group was significantly lower than that of middle SES group $(t=6.69, p<0.001)$, and psychological suzhi of middle SES group was significantly lower than that of high SES group $(t=9.23, p<0.001)$ (see Figure 1 ).

\subsection{Correlation and Regression Analysis of Parenting Style and Middle School Students' Psychological Suzhi}

The correlation between parenting style and total scores of middle school students' psychological suzhi was calculated. The results found that father's emotional warmth, mother's emotional warmth and middle school students' psychological suzhi had significant positive correlation ( $\mathrm{r}$ value was 0.31 and 0.29 respectively, $p<$ 0.001); in addition, father's rejection, mother's rejection, father's over protection, mother's over protection and middle school students' psychological suzhi had significant negative correlation ( $\mathrm{r}$ value was $0.34,0.30,0.28$ and 0.32 respectively, $p<0.001$ ). On the basis of correlation analysis, total scores of middle school students' psychological suzhi was considered as the dependent variable, and parenting behavior was considered as the independent variable to establish the regression equation (stepwise). The results found that father's emotional warmth and mother's emotional warmth significantly positively predicted psychological suzhi, and mother's rejection and father's over protection significantly negatively predicted psychological suzhi. See Table 1.

\subsection{Analysis on the Intermediary Effect of Parenting Style on SES and Psychological Suzhi of Middle School Students}

The total score of psychological suzhi of middle school students was considered as the dependent variable. Through a structural equation model, the integration of SES and parenting style was investigated. It was found that the model of the intermediary effect of parenting style on SES and psychological suzhi of middle school students was fitted well. $\chi^{2}=8102.21, d f=4012, p<0.001, \chi^{2} / \mathrm{df}=2.02$, RMSEA $=0.05$, NFI $=0.93$ and $\mathrm{CFI}=$ 0.92. The coefficient of each path shown in Figure 2 all reached the significant level. Among them, the partial intermediary effect of father's emotional warmth and mother's emotional warmth in SES and middle school

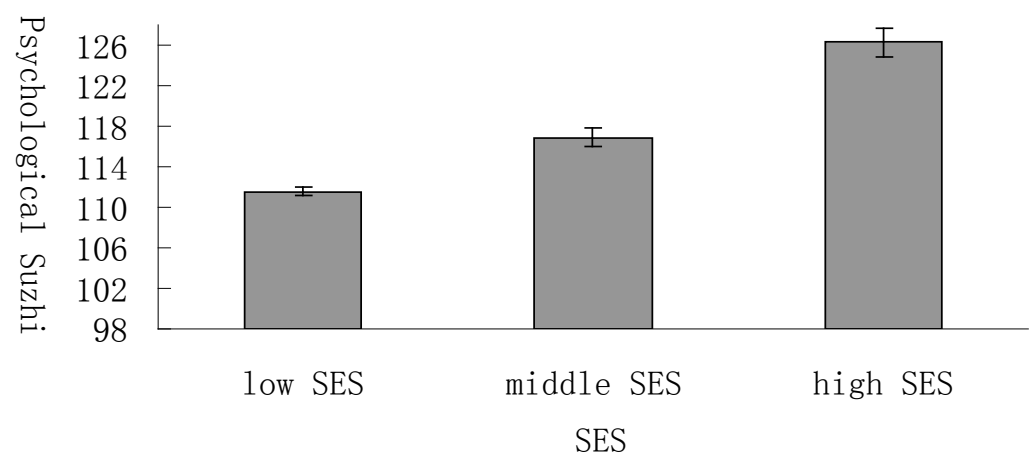

Figure 1. Comparison of psychological suzhi score of middle school students with different SES. 


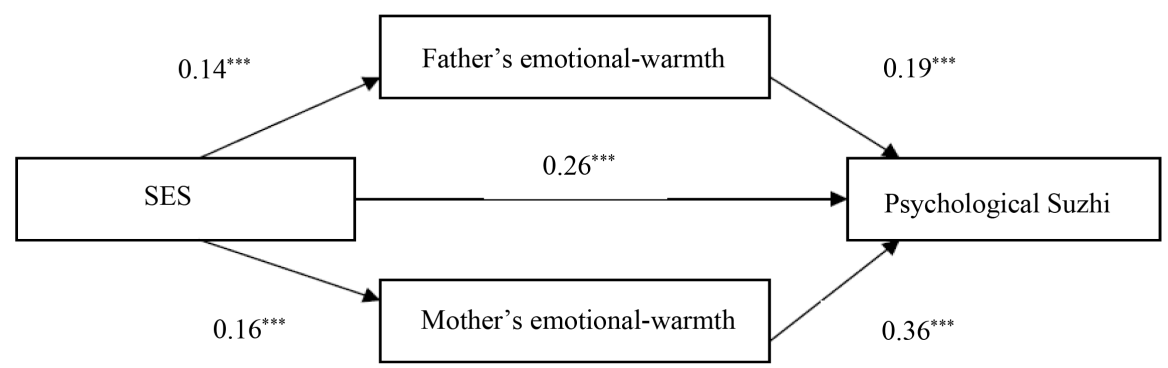

Figure 2. Analysis on the intermediary effect of parenting style on SES and psychological suzhi of middle school students.

Table 1. Regression analysis of parenting style and middle school students’ psychological suzhi.

\begin{tabular}{|c|c|c|c|c|c|c|}
\hline Outcome variable & $\begin{array}{l}\text { Predictive } \\
\text { variable }\end{array}$ & $\beta$ & $R$ & $R^{2}$ & $F$ & $t$ \\
\hline \multirow[t]{4}{*}{ Psychological suzhi } & Father's emotional warmth & 0.32 & 0.30 & 0.09 & 57.84 & $7.02^{* * *}$ \\
\hline & $\begin{array}{l}\text { Mother's emotional } \\
\text { warmth }\end{array}$ & 0.28 & 0.26 & 0.07 & 48.62 & $5.45^{* *}$ \\
\hline & Mother's rejection & -0.19 & 0.22 & 0.05 & 36.21 & $-4.16^{* *}$ \\
\hline & Father's over protection & -0.23 & 0.27 & 0.07 & 29.87 & $-3.91^{* *}$ \\
\hline
\end{tabular}

Note: ${ }^{* *} \mathrm{p}<0.01,{ }^{* * *} \mathrm{p}<0.001$, the same below.

students' psychological suzhi is as shown in Figure 2. The total interpretation ratio of SES and parenting style for middle school students' psychological suzhi was $19.21 \%$. Among them, the direct effect of father's emotional warmth and mother's emotional warmth was 0.19 and 0.36 , respectively. The direct effect, indirect effect and total effect of SES was $0.16,0.08$ and 0.24 , respectively.

\section{Discussion}

\subsection{The Relationship between SES and Middle School Students' Psychological Suzhi}

This study showed that SES and middle school students' psychological suzhi had significant positive correlation. Psychological suzhi of middle school students with high, middle and low SES had significant difference. According to the family investment theory, youth with favorable SES have more development capital, such as financial capital, time with parents, good parenting style and other social capital, so as to obtain a positive development; youth with low SES get less development capital, which hinders their positive development [10]. Studies have confirmed that SES has a significant influence on children's cognitive development. Lower SES could affect the development of working memory function and cognitive control function in children's executive function [11]; in addition, children with lower SES will had pessimistic, hostility, self-abasement and other characteristics, and are also more prone to life and learning adaption problems and low social ability [12]. The study results also support the family investment theory. Psychological suzhi is a psychological quality system consisting of cognitive quality, personality quality and adaptability. Higher education investment, good parenting style and others brought by high SES undoubtedly provide guarantee for the healthy development of component content of psychological suzhi of youth.

\subsection{The Relationship between Parenting Style and Middle School Students' Psychological Suzhi}

This study has found that parenting style has significant prediction effect on middle school students' psychological suzhi. Among them, mother's emotional warmth and father's emotional warmth significantly positively predict psychological suzhi. Mother's rejection and father's over protection significantly negatively predict psychological suzhi. When studying the relationship between parenting style and students' psychological suzhi, Gong Ling et al. (2014) found that psychological suzhi of college students with different parenting types had significant difference. The authoritative type was the best, arbitrary type and neglecting type were similar, and 
spoil type was the worst [13]. But parenting type and parenting style are quite different. Every parenting type can be a combination of a variety of parenting styles. For example, neglecting parenting type may mean less emotional warmth and understanding, less monitoring and protection, more indulging, etc. [14]. Therefore, the results of the study more clearly revealed the specific mode of action of different parenting types for psychological suzhi of youth.

\subsection{The Intermediary Effect of Parenting Style on SES and Psychological Suzhi of Middle School Students}

This study found that father emotional warmth and mother's emotional warmth had an intermediary effect on SES and middle school students' psychological suzhi. It also preliminarily revealed that SES affected the inner mechanism of middle school students' psychological suzhi. It means that SES not only affects middle school students' psychological suzhi directly, but also indirectly affects middle school students' psychological suzhi by affecting father's emotional warmth and mother's emotional warmth. The results also support the findings of previous research. As the physical environment of individual development, SES can not only directly affect the development of youth, but also play an important role on the development of individual by influencing the parenting style and parent-child interaction [15]. Family capital theory points out that factors such as education level and occupation of parents in SES manifest as not only difference in their own ability and skills, but also difference in the parenting style [16]. In the specific term, parents with high SES tend to have warm understanding parenting style, and more interaction and communication with children. Parents with low income control children more in parenting, emphasize on obedience and have less communication [17]. And the researchers point out that the higher SES is, the smaller the pressure of parenting style is, which can allow them to provide more education, support and care for their children. Parents with low SES often ignore emotional care and guidance to the children because they are busy making money [18].

\section{Limitations to the Study}

This was a cross-sectional study to clarify the role of SES in the relationship between the psychological suzhi and parenting style. The cross-sectional design of the study prohibits inference of causality so associations were determined. Social desirability compels participants to over-report (give certain desirable responses). For example, a middle school student might report the best performance in daily life. In view of this, future data collection would include interviews and case study for getting the more valid information.

\section{Conclusion}

The SES not only had independent prediction effect on middle school student's psychological suzhi, but also positively predicted psychological suzhi through father's emotional warmth and mother's emotional warmth by intermediary role. It was important to improve the level of SES of middle school students' family when promoting the psychological suzhi of middle school students.

\section{References}

[1] Su, Z.Q. and Zhang, D.J. (2015) The Relationship between Psychological Suzhi and Depression of Children 8 - 12 Years Old: The Intermediary Effect of Coping Style. Chinese Journal of Special Education, 2, 72-77.

[2] Liu, C.X. and Lei, Y. (2015) 30 Years of Psychological Suzhi Research: Looking Back and Evaluation. Journal of Southwest University (Social Science Edition), 41, 96-100.

[3] Zhu, X.R. and Zhang, H. (2013) Review of the Influence of Family’s Social Economic Status on Children's Development. Journal of Henan University (Social Science Edition), 53, 119-124.

[4] Matthews, K.A. and Gallo, L.C. (2011) Psychological Perspectives on Pathways Linking Socioeconomic Status and Physical Health. Annual Review of Psychology, 62, 501-530. http://dx.doi.org/10.1146/annurev.psych.031809.130711

[5] Gong, X.L., Liu, C.C. and Wei, X.J. (2012) Related Research of Family’s Social Economic Status, Parenting Style and Children's Rights Consciousness. Journal of Special Education in China, 1, 85-89.

[6] Keller, B.K. and Whiston, S.C. (2008) The Role of Parental Influences on Young Adolescent's Career Development. Journal of Career Assessment, 16, 198-217. http://dx.doi.org/10.1177/1069072707313206

[7] Shi, B.G. and Shen, J.L. (2007) The Relationship between Family’s Social Economic Status, Intelligence and Internal 
Motivation and Creativity. Journal of Psychological Development and Education, 1, 30-33.

[8] Jiang, J., Lu, Z.R., Jiang, B.J. and Xu, Y. (2010) Preliminary Revision of Chinese Version of Simplified Parenting Style Questionnaire. Journal of Psychological Development and Education, 1, 94-99.

[9] Zhang, J., Liang, Y.H., Su, Z.Q., Chen, G. and Zhang, D.J. (2015) The Relationship between Middle School Student’s Psychological Suzhi and Positive Emotions: The Intermediary Effect of Emotional Elasticity. Chinese Journal of Special Education, 9, 71-75.

[10] Chen, Y.H., Cheng, G., Guan, Y.S. and Zhang, D.J. (2014) College Student's Objective Social and Economic Status and Self-Esteem: The Intermediary Effect of Subjective Social Status. Journal of Psychological Development and Education, 6, 594-600.

[11] Hackman, D.A. and Farah, M.J. (2009) Socioeconomic Status and the Developing Brain. Trends in Cognitive Sciences, 13, 65-73. http://dx.doi.org/10.1016/j.tics.2008.11.003

[12] Luo, X.L. and Li, T.R. (2015) The Influence of Family's Social Economic Status on Peer Relation of Left-Behind Children. Journal of Special Education in China, 2, 78-83.

[13] Gong, L., Zhang, D.J. and Wang, J.L. (2013) Investigation and Evaluation of the Contemporary College Student's Psychological Suzhi in China. Journal of Southwest University (Social Science Edition), 39, 71-76.

[14] Qu, K.J. and Zou, H. (2013) The Relationship between Family’s Social Economic Status, Parenting Style Behavior and College Student's Career Exploration. Journal of Psychological Development and Education, 5, 500-506.

[15] Bradley, R.H. and Corwyn, R.F. (2002) Socioeconomic Status and Child Development. Annual Review of Psychology, 53, 371-399. http://dx.doi.org/10.1146/annurev.psych.53.100901.135233

[16] Li, J.Q. and Man, H.D. (2013) The Relationship between Family’s Social Economic Status and Creative Thinking: Intermediary, Compensation and Adjustment Effect of Parenting Style. Journal of Youth Studies, 3, 1-6.

[17] Conger, R.D. and Donnellan, M.B. (2007) An Interactionist Perspective on the Socioeconomic Context of Human Development. Annual Review of Psychology, 58, 175-199. http://dx.doi.org/10.1146/annurev.psych.58.110405.085551

[18] Gauvain, M. and Huard, R.D. (1999) Family Interaction, Parenting Style, and the Development of Planning: A Longitudinal Analysis Using Archival Data. Journal of Family Psychology, 13, 75-92.

http://dx.doi.org/10.1037/0893-3200.13.1.75 


\section{Appendix}

1) Middle School Student’s Psychological Suzhi Questionnaire (part items)

Filling explanation: Please choose the number that best reflects your actual situation in daily life, and " 1 " means "totally disagree”, “2” means "strongly disagree”, “3” means “uncertain”, “4” means "strongly agree”, “5” means "totally agree".

\begin{tabular}{lcccccc} 
& Item & $\begin{array}{c}\text { Totally } \\
\text { disagree }\end{array}$ & $\begin{array}{c}\text { Strongly } \\
\text { disagree }\end{array}$ & $\begin{array}{c}\text { Uncertain } \\
\text { Strongly } \\
\text { agree }\end{array}$ & $\begin{array}{c}\text { Totally } \\
\text { agree }\end{array}$ \\
\hline 1 & I can always be the master of my studies. & 1 & 2 & 3 & 4 & 5 \\
2 & I can well integrate and adapt to the society & 1 & 2 & 3 & 4 & 5 \\
3 & In public, I always have a good idea and express it. & 1 & 2 & 3 & 4 & 4 \\
4 & I like to delve into problems. & 1 & 2 & 3 & 4 & 5 \\
\hline
\end{tabular}

2) Chinese Version of Simplified Parents Parenting Questionnaire (S-EMBU-C) (part items)

Filling explanation: Please try to think back in the growing process of parenting and choose the number that best reflects the actual situation in your family life. Each question was divided into two forms including father's parenting style and mother's parenting style, and if you come from a single-parent family, you can only fill in a father or mother of that.

\begin{tabular}{|c|c|c|c|c|c|c|c|c|c|}
\hline & \multirow{2}{*}{ item } & \multicolumn{4}{|c|}{ Father } & \multicolumn{4}{|c|}{ Mother } \\
\hline & & Never & Occasionally & Often & Always & Never & Occasionally & Often & Always \\
\hline 1 & $\begin{array}{l}\text { My parents lost their temper to me } \\
\text { without reason. }\end{array}$ & 1 & 2 & 3 & 4 & 1 & 2 & 3 & 4 \\
\hline 2 & Parents praised me. & 1 & 2 & 3 & 4 & 1 & 2 & 3 & 4 \\
\hline 3 & $\begin{array}{l}\text { I hope my parents not to worry too } \\
\text { much about what I am doing. }\end{array}$ & 1 & 2 & 3 & 4 & 1 & 2 & 3 & 4 \\
\hline 4 & $\begin{array}{l}\text { My parents' punishment is often } \\
\text { more than I deserve }\end{array}$ & 1 & 2 & 3 & 4 & 1 & 2 & 3 & 4 \\
\hline 5 & $\begin{array}{l}\text { My parents asked me to go back } \\
\text { home and have to show them what I } \\
\text { did on the outside. }\end{array}$ & 1 & 2 & 3 & 4 & 1 & 2 & 3 & 4 \\
\hline
\end{tabular}

3) SES Questionnaire

a) Education level of father:

(1) Illiterate; (2) graduate from primary school; (3) graduate from middle school; (4) graduate from high school or technical secondary school; (5) graduate from university or college

b) Education level of mother:

(1) Illiterate; (2) graduate from primary school; (3) graduate from middle school; (4) graduate from high school or technical secondary school; (5) graduate from university or college

c) Father's job: ; Mother's job: 